\title{
A Novel Experimental Model for Dental Implant Research
}

\author{
${ }^{1}$ Murude Yazan, ${ }^{2}$ Fethi Atil, ${ }^{3}$ Zeynep B Gonen, ${ }^{4}$ Ismail D Kocyigit, ${ }^{5}$ Umut Tekin
}

\begin{abstract}
Introduction: Femur, tibia and iliac bone have been generally preferred at previous experimental implant investigations. Bone mineral density, corticocancellous content of these regions are different from jaws because of having endochondral origins. Immobilization and animal care are difficulties of animal studies used extremities. This study aims to describe a new animal model for experimental dental implant research by using rabbits' mandibles to eliminate disadvantages of other defined regions.
\end{abstract}

Materials and methods: Custom designed and produced implants were implemented at identified mandibular molar areas of 10 male New Zealand rabbits adequately far away to teeth apices and mental foramen. Four $\mathrm{mm}$ lengthened, 2.8 $\mathrm{mm}$ diameter SLA Nucleoss (İzmir, Turkey) specially produced micro dental implants were placed at identified regions of rabbits' mandibles. Two implants were used for each rabbit. Osseointegration was observed two months after the operation histomorphology.

Results: Osseointegration was not actualized at around three implants and finished successfully without infection at around all other implants. Newly formed osteoid matrix and bone tissue were evaluated in all specimens histologically except three implants. This new mandible implant model presumedly shows more similar results about osseointegration to human experiments because of the intramembranous ossification. This model prevents the movement difficulty and fracture risk caused by extremities usage. Postoperative care gets easier, and surgical approach is more invasive than previously used experimental studies in this model.

Conclusion: Specially designed mini implants and more sensitive manipulation are necessities of this new approach. Previously used rabbit models can be compared with this mandible model with regard to implant osseointegration.

Keywords: Animal, Experimental, Implant, Model.

How to cite this article: Yazan M, Atil F, Gonen ZB, Kocyigit ID, Tekin U. A Novel Experimental Model for Dental Implant Research. Int J Experiment Dent Sci 2018;7(2):43-47.

Source of support: Nil

Conflict of interest: None

\footnotetext{
${ }^{1,3}$ Assistant Professor, ${ }^{2,4}$ Associate Professor, ${ }^{5}$ Professor

${ }^{1}$ Department of Oral and Maxillofacial Surgery, Biruni University, Istanbul, Turkey

2,4,5 Department of Oral and Maxillofacial Surgery, Kirikkale University, Kirikkale, Turkey

${ }^{3}$ Department of Oral and Maxillofacial Surgery, Erciyes University, Kayseri, Turkey
}

Corresponding Author: Murude Yazan, Assistant Professor, Department of Oral and Maxillofacial Surgery, Biruni University, Istanbul, Turkey, e-mail: murudeyazan@hotmail.com

\section{INTRODUCTION}

Dental implants are contemporarily used for rehabilitation of completely and partially edentulous patients. Branemark et al. described direct bone-to-implant contact firstly with the expression of "osseointegration". . Osseointegration was later defined as "a direct functional and structural contact between living and organized bone and the surface of a load bearing implant ${ }^{\prime 2}$ It has been a contradictive definition because it does not define the resolution level of observation and does not include the estimated percentage of this contact to justified the use of the term. The term 'osseointegration' is a histological definition; thus, experimental investigations on osseointegration should include a careful quantitative evaluation of direct bone contact to the implanted substrate using clinical, radiological and histological concepts.

Different implant designs and surface modifications have been researched to guide successful healing at bone-implant interface and optimize of implant characteristics. Development of an optimal interface between bone and dental implants is a challenge which has taken place for many years. Development of implant type investigations demand the requirements of biocompatibility, mechanical stability, and optimal bone-implant interactions; experimental animal models are often essential for testing dental implants before clinical usage.

Numerous animal models have been preferred for testing the biological performance and biocompatibility of newly developed implants. Rabbit is one of the most commonly used animal models for medical research, being used in approximately $35 \%$ of musculoskeletal research studies. ${ }^{3}$

The most commonly used models for bone-implant interactions and osseointegration mechanism are tibia and femoral condyle which have an endochondral origin. ${ }^{4}$ More than one implant usage is possible at these bigger areas, but the differences caused by ossification type cannot be ignored for dental implant studies.

Our purpose is minimizing the differences between animal studies' and human response to dental implant researches which are caused by different ossification mechanisms and eliminating the disadvantages of other experimental models. 


\section{MATERIALS AND METHODS}

This study was supported by Scientific Research Project Unity of Kirikkale University. Ethical consent was received by the Local Animal Studies Ethics Committee of Kirikkale University at the date of 16/12/2013. The study was actualized at Huseyin Aytemiz Animal Research Laboratory of Kirikkale University.

Ten New Zealand rabbits, ten weeks aged and weighted $2.5 \mathrm{~kg}$ were used for the study. Experimental animals were kept at properly sized cages had $22 \pm 2^{\circ} \mathrm{C}$ temperature. The environment was lightened along 12 hours and darkened along 12 hours.

Xylazine ( $5 \mathrm{mg} / \mathrm{kg}$, Rompun, Bayer, Germany) and Ketamine $\mathrm{HCl}$ (50 mg/kg, Ketalar, Eczacibasi, Istanbul) were injected intramuscularly for general anesthesia. Operation areas were disinfected with povidone-iodine (Betadine, Kansuk Lab. Istanbul, Turkey). Articaine HCI (Ultracain DS-forte Sanofi-Aventis Deutschland, Germany) was injected locally to the operation sites for vasoconstriction. About $2.5 \mathrm{~cm}$ skin incision was done parallelly to the mandible inferior border. A mucoperiosteal flap was elevated with subperiosteal dissection (Fig. 1). The mental nerve was protected while flapping dissection. Dental implants had $2.8 \mathrm{~mm}$ diameter and $4 \mathrm{~mm}$ length (Nucleoss, Izmir, Turkey) were specially designed for the study (Fig. 2). Rabbits' mandibles molar area that had enough distance from molar teeth apices were determined for operation site. Two implant cavities were prepared at determined regions. Minimum 2-3 $\mathrm{mm}$ safe distance was left between two implants. Flatted healing cap was screwed after installation.

Flaps were adapted for tension-free wound closure with interrupted sutures by layer to layer.
The incised area was sutured subcutaneously with 4.0 polyglycolic acid (Vicryl-Johnson and Johnson, Someville, $\mathrm{ABD}$ ) and cutaneously with 4.0 polypropylene (Polipropilen-Ethicon, Somerville, ABD). Enrofloxacin (Enofilin $2.5 \mathrm{mg} / \mathrm{kg}$ IM, Arma, Ankara, Turkey) and meloksikam (Maxicam $1 \mathrm{mg} / \mathrm{kg}$ IM, Cravinhos, Brazil) were injected intramuscularly during the postoperative period for 5 days. The sutures were removed after two weeks. Rabbits were followed 2 months after the operation for implants' osseointegration. Newly formed osteoid matrix and bone tissue were evaluated in all specimens histologically with an intracardiac injection of Xylazine $\mathrm{HCl}$ (30 mg/kg Rompun IM) and Ketamine $\mathrm{HCl}$ (70 mg/ $\mathrm{kg}$ Alfamine IM). The mandibles are dissected and saved at $10 \%$ formaldehyde solution.

\section{Histological Examination}

Preparation of histological preparets was actualized at Research Laboratory of Erciyes University Dentistry Faculty. Fixed specimens dehydrated with alcohol solutions. Dehydrated specimens processed with methacrylate resin for plastic infiltration. Plastic infiltrated specimens were placed at burial molds. The molds were filled with resin and then vacuumed. Yellow and blue lights were used for polymerization. Polymerized tissues were extracted from the burial molds. Polymerized molds were pasted to plexiglass with the adhesive press. Plexiglass molds were cut that crossed implants' central line. Micro erosion procedure was applied with emery machines. Forty $\mu \mathrm{m}$ histological sections were gained with using sensitive cutting machines. The preparates were washed with $10 \%$ hydrogen peroxide and then imbrued with Goldner-Trikrom technique.

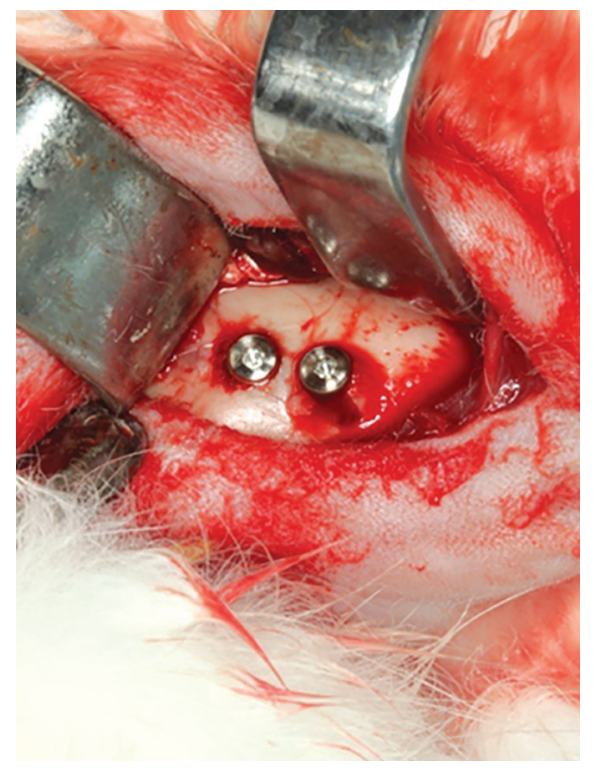

Fig. 1: Surgical implantation

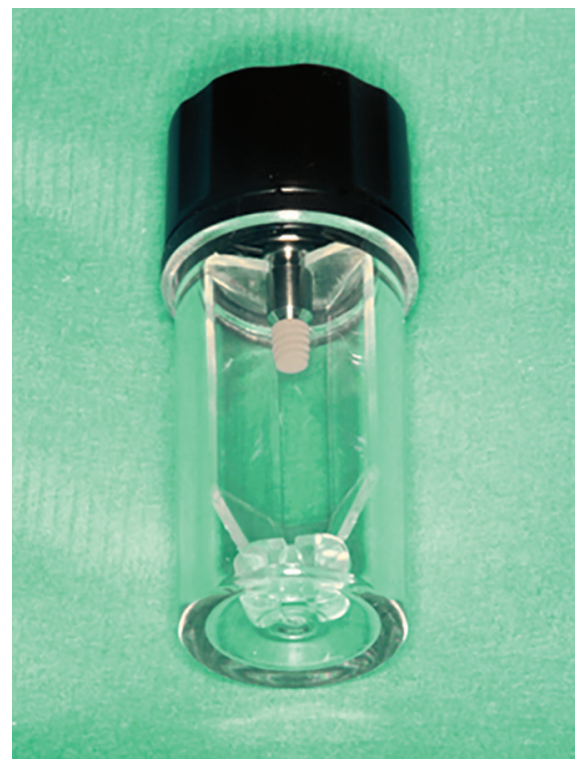

Fig. 2: Specially designed implants 
A Novel Experimental Model for Dental Implant Research

\section{Histomorphometric Analysis}

Digital images were obtained with a digital camera connected with a light microscope. These images analyzed histomorphometrically with Olympus Analysis LS Research computer program (AnalySIS LS Research, version 5.0, Olympus Soft Imaging Solutions).

\section{Statistical Evaluation}

BM statistical package for social sciences statistics 22 (IBM SPSS, Turkey) was used to evaluate the findings of the study. For defining quantitative data, arithmetic average and standard deviation were used. The suitability of study data and normal distribution was evaluated with ShapiroWilk's test. Comparison between the groups was utilized with a t-test. A $p<0.05$ was evaluated as relevance level.

\section{RESULTS}

Osseointegration wasn't actualized at around three implants and finished successfully without infection at around all other implants. Newly formed osteoid matrix and bone tissue were evaluated in all specimens histologically except three implants (Fig. 1).

According to the results; bone area scores' mean was $2697.70 \pm 1605.80$, bone and osteoid tissue area scores' mean was $4704.05 \pm 2935.89$, bone area percentage was $24,00 \pm 13,73 \%$, bone, and osteoid tissue percentage was 65,03 \pm 20,29\% (Table 1).

Postoperative care is easier from other animal models at rabbits. Rabbits are big enough for the placement of multiple implants. Because of their size and temperament, rabbits are easy to handle and it is possible to keep and observe many at the same time. They are readily available and less expensive than larger animals.

Generally used models, such as tibia and femoral condyle have an endochondral origin. There are some differences between endochondral and intramembranous ossification mechanisms. The new rabbit mandible model described in this experimental study in an attempt to show more similar results to human experiments using intramembranous ossification. All implants except three non-osseointegrated implants were stable two months later after the operation. There were not seen any complications such as postoperative infection, implant or mandible fracture. This new mandible implant model prevented the movement difficulty and fracture risk caused by extraoral regions' usage. This approach was minimal invasive when compared with other regions' usage.

\section{DISCUSSION}

To supply successful healing at the bone-implant interface and enhance implant characteristics, several implant
Table 1: Histomorphometrical analysis

\begin{tabular}{llll}
\hline Ort \pm SS & $\begin{array}{l}\text { Ort } \pm \text { SS } \\
\text { Bone }+ \text { osteoid }\end{array}$ & $\begin{array}{l}\text { Ort } \pm \text { SS } \\
\% \text { Kemik }\end{array}$ & $\begin{array}{l}\text { Ort } \pm \text { SS \% } \\
\text { Kemik + osteoid }\end{array}$ \\
\hline Bone area & area & $\begin{array}{l}\% 24,00 \pm \\
13,73\end{array}$ & $\% 65,03 \pm 20,29$ \\
\hline $2697.70 \pm$ & $4704.05 \pm$ & & \\
1605.80 & 2935.89 & & \\
\hline
\end{tabular}

designs have been researched. Use of an animal model is often an essential step in the testing of dental implants before clinical usage. Animal studies are useful to test the biocompatibility and functionality of a newly designed implant. It should be emphasized; however, animal studies will never be able to fully represent the clinical situation in humans.

The rabbit is one of the most commonly used animal models for medical research, being used in approximately $35 \%$ of musculoskeletal research studies. ${ }^{3}$ There are differences in the bone anatomy between the rabbit and human both in the size and shape of the bones. Rabbit long bones have various differences microstructurely from humans. ${ }^{5}$ Rabbits have a primary vascular longitudinal tissue structure, comprising vascular canals of osteons running parallel with the long axis of the bone, surrounding the medullary canal as well as the periosteal surface. ${ }^{6}$ Some resemblances are found between rabbits and humans with regard to bone mineral density (BMD) and the fracture toughness of mid-diaphyseal bone. ${ }^{6}$ Rabbits' skeletal change and bone turnover faster than humans. ${ }^{7}$ But this situation can be an advantage for rapid osseointegration process and study time shortens. Rabbits' postoperative care is easier from other animal models. Rabbits are big enough for the placement of multiple implants. The international standard for biological evaluation of medical devices recommends a maximum of 6 implants/rabbit, the same recommendation for the larger animals are 12 (International Standard ISO 10993$6,1994)$. The recommended size for screw-type implants placed in the mid shaft (diaphyseal) cortical rabbit bone is 2-4.5 mm (International Standard ISO 10993-6, 1994). The standard does not state if this is the diameter or the length. For cylindrical implants, the recommended size is $2 \mathrm{~mm}$ in diameter and $6 \mathrm{~mm}$ in length (International Standard ISO 10993-6, 1994). Because of their size and temperament rabbits are easy to handle and it is possible to keep and observe many at the same time. They are readily available and less expensive than larger animals and are more accepted as experimental animals. It is also convenient that rabbits develop and reach skeletal maturity fast.

The most commonly used models for bone-implant interactions are tibia and femoral condyle which have an endochondral origin. ${ }^{4}$ These bones include much more 
spongiosus content than cortical content. Sennerby et al. used the tibial metaphyses as sites resembling mandible with having more compact bone and the epiphysis of the femur in the knee joint as a site resembling maxilla with having more cancellous bone. ${ }^{8}$ The cortical thickness of the rabbit tibial diaphysis and metaphyses is about 1.2-1.5 $\mathrm{mm}$ and the length of the bone in a full-grown rabbit is about $11 \mathrm{~cm} .{ }^{9}$ A disadvantage with placing the implant in long bones instead of the jaws is that loading it with a dental prosthesis is not possible.

\section{Tibia}

The medial or lateral side of the tibia has been extensively used as the area for implant placement in different animal models. Two implants can be placed bilaterally in both tibiae.

\section{Femoral Condyle}

Another frequently preferred region is femoral condyle for implant investigations. Surgical approach and implantation area can vary between different animal models. The most common approach comprises a longitudinal incision over the medial or lateral surface of the femoral condyle. Two implants could be placed at per site in rabbits.

\section{Iliac Crest}

The iliac crest in goats was used to a new approach that allows implantation of up to five dental implants per iliac crest in a study which was made at $2010 .^{10}$

Previously used regions of different animals for implant studies have an endochondral origin. Mandible has intramembranous origin and usage of mandible models for dental experimental implant studies could show more simultaneous results with humans. There are some differences between two ossification mechanisms (Table 2).

Intramembranous ossification: The embryonic model for most flat bones and a few other bones is a sheet of dense fibrous connective tissue; stem cells differentiate into osteoblasts which begin laying down bone matrix in a spongious bone pattern to replace the fibrous membrane model; several such centers of ossification expand until they meet and fuse; eventually the entire structure matures to have compact bone on the outer surface and spongy bone in the interior.

Endochondral ossification: The embryonic model for most long, short and irregular bones is a mass of dense fibrous connective tissue; stem cells differentiate into chondroblasts which begin laying down hyaline cartilage matrix in a pattern to replace the fibrous connective tissue model;
Table 2: Differences between two ossification mechanisms

\begin{tabular}{|c|c|c|}
\hline $\begin{array}{l}\text { Characteristic } \\
\text { differences }\end{array}$ & $\begin{array}{l}\text { Intramembranous } \\
\text { ossification }\end{array}$ & $\begin{array}{l}\text { Endochondral } \\
\text { ossification }\end{array}$ \\
\hline $\begin{array}{l}\text { Bone type(s) } \\
\text { involved }\end{array}$ & Most flat bones & $\begin{array}{l}\text { Most long, short and } \\
\text { irregular bones }\end{array}$ \\
\hline $\begin{array}{l}\text { Embryonic } \\
\text { model }\end{array}$ & $\begin{array}{l}\text { A sheet of dense } \\
\text { fibrous connective } \\
\text { tissue }\end{array}$ & $\begin{array}{l}\text { Dense fibrous connective } \\
\text { tissue is replaced } \\
\text { by hyaline cartilage } \\
\text { matrix }\end{array}$ \\
\hline $\begin{array}{l}\text { Stem cells } \\
\text { involved }\end{array}$ & $\begin{array}{l}\text { Fibroblasts, } \\
\text { osteoblasts }\end{array}$ & $\begin{array}{l}\text { Fibroblasts, } \\
\text { chondroblasts, } \\
\text { osteoblasts }\end{array}$ \\
\hline $\begin{array}{l}\text { Progression of } \\
\text { developing } \\
\text { tissue types }\end{array}$ & $\begin{array}{l}\text { Dense fibrous } \\
\text { connective } \\
\text { tissue } \rightarrow \text { bone }\end{array}$ & $\begin{array}{l}\text { dense fibrous connective } \\
\text { tissue } \rightarrow \\
\text { hyaline cartilage } \rightarrow \\
\text { bone }\end{array}$ \\
\hline $\begin{array}{l}\text { Marrow space in } \\
\text { the adult bone }\end{array}$ & Unlikely & Likely \\
\hline
\end{tabular}

then osteoclasts and blood vessels penetrate the cartilage while other stem cells follow and differentiate into osteoblasts which begin laying down bone matrix in a spongy bone pattern to replace the cartilage model; several such centers of ossification expand until they meet and fuse; eventually the entire structure matures to have compact bone on the outer surface and to have spongy bone and possibly a marrow space in the interior.

Different rabbit mandible models have been used for researches of bone augmentation procedures, wound healing examinations, distraction osteogenesis studies. However, rabbit mandible models haven't been used for dental implant researches before.

Benlidayi et al. used rabbit mandible models to evaluate the osseointegration of three different bone grafting techniques. ${ }^{11}$ Horizontal augmentation was performed on the corpus of the mandible using three different techniques-free bone graft (FBG), free periosteal bone graft (PBG), pedicled bone flap (BF). BF demonstrated greater osseous healing capacity compared to FBG and PBG. The preserved vascularization in BF improved the bone quality in mandibular bone augmentations.

Lai et al. investigated the effects of local delivery of adipose-derived stem cells (ADSCs) transfected with transcription factor osterix (OSX) on bone formation during distraction osteogenesis in rabbit mandible models. ${ }^{12}$ The results indicated that the transplantation of ADSCs transfected with pEGFP-OSX can effectively promote bone generation during distraction in vivo. Local delivery osteopromotive factors like ADSC s could be used in dental implant investigations at this described rabbit mandible model.

Veis et al. researched vertical bone regeneration outcomes after using bovine bone graft material in the block and granular forms in rabbit mandible models. ${ }^{13}$ The new bone was observed mostly close to the basal bone and developed penetrating the trabecular scaffold in the form 
of seams that covered the intra-lumen surfaces of the block type graft while in the granular graft type the new bone was observed to grow between the graft particles usually interconnecting them. Bone grafts of membranous origin resorb significantly less than endochondral bone grafts. Different micro-architecture and vascularization are considered as the cause of this situation. Osseointegration indicates differences based upon the same reasons between different ossification mechanisms.

Zhang et al. examined the healing of critical-size surgical defects after implantation of porous nano-hydroxyapatite/polyamide composite (nHA/PA) block based on a bilateral mandible model using rabbits. ${ }^{14}$ The porous nHA/PA composite promoted bone formation over the extension of the defect, particularly in the early stage.

The new rabbit mandible model described in this experimental study in an attempt to show more similar results to human experiments by means of intramembranous ossification.

All implants except three non-osseointegrated implants were stable two months later after the operation. There were not seen any complications such as postoperative infection, implant or mandible fracture. This new mandible implant model prevented the movement difficulty and fracture risk caused by extraoral regions' usage. This approach was minimal invasive when compared with other regions' usage.

Despite histopathological examination, the rabbits can be alive. Smaller histopathological specimens could be enough when specially produced smaller implants are used at rabbits' mandibles. But rabbits were sacrificed in this study.

Specially designed mini implants and more sensitive manipulation are necessities of this new approach. Previously used rabbit models can be compared with this mandible model with regard to implant osseointegration.

A disadvantage with placing the implant in long bones instead of the jaws is that loading it with a dental prosthesis is not possible. Prosthetic loading could be experienced at further rabbit mandible studies.

\section{CONCLUSION}

Specially designed mini implants and more sensitive manipulation are necessities of this new approach. Previously used rabbit models can be compared with this mandible model with regard to implant osseointegration.

A disadvantage with placing the implant in long bones instead of the jaws is that loading it with a dental prosthesis is not possible. Prosthetic loading could be experienced at further rabbit mandible studies.

\section{REFERENCES}

1. Branemark PI, Hansson BO, Adell R, et al. Osseointegrated implants in the treatment of the edentulous jaw. Experience from a 10 year period. Scand J Plast Reconstr Surg Suppl, 1977;16:1-132.

2. Zarb GA, Albrektsson T. Osseointegration: A requiem for the periodontal ligament? International Journal of Periodontics and Restorative Dentistry 1991;11:88-91.

3. Neyt JG, Buckwalter JA, Carroll NC. Use of animal models in musculoskeletal research. Iowa Orthop J 1998;18:118-123.

4. Schouten C, van den Beucken JJ, de Jonge LT, et al. The effect of alkaline phosphatase coated onto titanium alloys on bone responses in rats. Biomaterials 2009;30(32):6407-6417.

5. Wang X, Mabrey JD, Agrawal CM. An interspecies comparison of bone fracture properties. Biomed Mater Eng 1998;8(1):1-9.

6. Martiniakova M, Omelka R, Chrenek P, et al. Changes of femoral bone tissue microstructure in transgenic rabbits. Folia Biol (Praha) 2005;51(5):140-144.

7. Castaneda S, Largo R, Calvo E, et al. Bone mineral measurements of subchondral and trabecular bone in healthy and osteoporotic rabbits. Skeletal Radiol 2006;35(1):34-41.

8. Albrektsson, T, Sennerby L, Wennerberg A. State of the art of oral implants. Periodontology 2008;47:15-26.

9. Susin C, Qahash M, Hall J, et al. Histological and biomechanical evaluation of phosphorylcholine-coated titanium implants. Journal of Clinical Periodontology 2008;35:270-275.

10. Schouten C, Meijer GJ, Van Den Beucken JJ, et al. A novel implantation model for evaluation of bone healing response to dental implants: the goat iliac crest. Clin Oral Impl Res 2010;21(4):414-423.

11. Benlidayi ME, Tatli U, Kurkcu M, et al. Comparison of bovinederived hydroxyapatite and autogenous bone for secondary alveolar bone grafting in patients with alveolar clefts. J Oral Maxillofac Surg 2012;70(1):e95-102.

12. Lai QG, Sun SL, Zhou XH, et al. Adipose-derived stem cells transfected with pEGFP-OSX enhance bone formation during distraction osteogenesis. J Zhejiang Univ Sci B 2014;15(5):482490.

13. Veis A, Dabarakis N, Koutrogiannis C, et al. Evaluation of Vertical Bone Regeneration Using Block and Particulate Forms of Bio-Oss Bone Graft: A Histologic Study in the Rabbit Mandible. J Oral Implantol 2015;41(3):e66-72.

14. Zhang JC, Lu HY, Lv GY, et al. The repair of critical-size defects with porous hydroxyapatite/polyamide nanocomposite: an experimental study in rabbit mandibles. International Journal of Oral and Maxillofacial Surgery 2010;39(5):469-477. 